\title{
IMPULSIVITY AND SELF-HARM BEHAVIOR IN YOUNG ADULT WOMAN WITH AUTHORITATIAN PARENTING: A CASE REPORT
}

\author{
Asy Syifa Karima ${ }^{1 ;}$ Zuhrotun Ulya $^{2}$ \\ Correspondence: syifamulia14@gmail.com \\ ${ }^{I}$ General Practitioner, Indonesia; ${ }^{2}$ Psychiatric Department Medical Faculty University of Brawijaya
}

\section{Article History:}

Received: April 19, 2021

Accepted: June 28, 2021

Published: September 30, 2021
Cite this as: Karima, A.S. Ulya, Z. Impulsivity and self-harm behavior in young adult woman with authoritarian parenting: a case report. Journal of Psychiatry Psychology and Behavioral Research; 2021. Vol 2, Issue 2. p :4-

\section{INTRODUCTION}

Impulsivity (or impulsiveness) is a variety of factors that makes a person of his own accord tend to act or behave without or with little consideration of the consequences, reflections and forward thinking. ${ }^{1}$ Impulsivity also a risk factor for various maladaptive outcomes in early adulthood and adolescence. ${ }^{2}$ One of the cause of leading impulsivity is the parenting styles adopted by the parents. ${ }^{1}$

Self-harming behaviors such as self-mutilation, selfimmolation, self-punishment, and substance abuse are significantly more common in adolescence than in other age groups. Maladaptive cognitive emotion regulation strategies had a positive significant relationship with self-harm behaviors. However, authoritarian parenting had no direct impact on selfharming behavior, but after mediation by maladaptive cognitive emotion regulation strategies, their effects on self-harming behaviors were reported. ${ }^{3}$

Adolescence is often termed as an age of storm and stress since one's cognition, emotion, behaviour and conglomeration of personality functioning become crystallized in this phase. Any deviation from the normal developmental pathway may lead to psychopathology. There are several genetic and environmental factors that affect adolescent's development among which parenting plays a significant role. ${ }^{4}$

Parenting styles describe how parents demand and respond to their children. are the representation of how parents respond and demand to their children. ${ }^{1}$ According to Baumrind, there are 3 types of parenting, namely, athoritative parenting, permissive parenting, and authoritarian parenting. Authoritative parenting is a child-centered approach with high expectations of maturity. This is the best parenting style with a good prognosis where parents still limit their child's actions but also encourage them to be independent. In permissive parenting, parents are not demanding but still responsive. In indulgent parenting, parents are slightly demanding but unresponsive. In neglectful parenting, parents are neither responsive nor demanding to be unrestricted and very lacking in warmth and control. In authoritarian parenting, parents are demanding and not responsive, thus limiting children and discipline with punishment. Children must also follow parental directions without providing explanation or feedback. Yelling 
and scolding and corporal punishment are often used in authoritarian parenting. ${ }^{1,5}$ Authoritarian parents are sometimes inconsistent with rules. ${ }^{6}$ Authoritarian parents insist on expecting their children to obey their rules in total obedience. ${ }^{7}$.

\section{CASE}

Woman, 21 y.o, came to the Psychiatry Clinic with chief complaints of uncontrolled emotions, throwing things and hurting herself (hitting her head). The patient first became aware of having uncontrolled emotions since the age of 12 years (grade 1 junior high school). The patient feels very irritable and very sensitive to the little things. She feels satisfied if she has thrown an object or hit his own head, otherwise she will feels nauseous until her vision becomes blurry. There was a time when she was so passionate about her hobby (designing pictures) that she stays up late at night.

When she was 3 years old, she often witnesses her parents arguing violently. Since then she has been terrified whenever she is yelled at or scolded. The patient is the first of three children and lives at home with her parents and younger siblings. She is currently studying for the final semester and working as a private tutor. The relationship between the patient and the her parents was not good. Her father works out of town and comes home once a month. Her father is quite strict in his religion and tends to be authoritarian in leading the family. The patient feels that her father always forces her to do his orders, but when she has done it, she feels that her father does not appreciate it. Her father often scolded, hit, and threw things when he was angry. The patient also feels that her mother does not care about her condition. The relationship between the patient and her paternal grandmother is also bad. Her grandmother who lives next door also has uncontrollable emotions, often gets angry and throws things. This makes her uncomfortable to stay at home. The patient thinks that she is stiff and difficult to get along and closes herself from her friends and environment.

On physical examination, the generalist status was within normal limits. At mental status, appearance was appropriate for age, cooperative and psychomotor were normal. Depressive moods were found with shallow affects, a flow of thought coherent with the content of preoccupation, impulsivity, depersonalization, derealization, self-injurious ideas and behaviors. Awareness, orientation, memory, concentration and attention, value power, and cognitive abilities were good. The patient's surveillance degree is grade 4 (the patient understands that he is sick but does not know why). The patient was then carried out a psychiatric interview and an examination of his generalist status and mental status. After that, a literature review was carried out on the findings of the case.

\section{RESULT AND DISCUSSION}

In this case, the patient is a young adult woman who is also the first child in her family. There is a significant difference between men and women for the perception of stress and impulsive behavior with higer rates in men. ${ }^{1} \mathrm{~A}$ father tends to behave authoritatively in young women where they need more gentle interactions so they tend not to accept authoritarian parenting than boys. ${ }^{8}$ Therefore, girls who receive authoritarian parenting tend to be more likely become maladaptive and impulsive. Authoritarian parenting also known to have a significant relationship with birth order. ${ }^{8}$ According to Ahmad et. al., in girls aged 6-12 years who have very authoritarian mothers, impulsive and impulsive symptoms are found and predicted and these behavior will develop and increase such as becoming aggressive or commiting criminal acts in adolescence and can persist into early adulthood. ${ }^{9}$

In this case the patient received paternal authoritarian parenting and maternal permissive parenting. According to Kuppents, et. al., children whose parents are both authoritarian the neglectful parenting style showed the poorest behavioral outcomes while children whose parents use authoritative parenting coincides most with positive developmental outcomes. ${ }^{11}$ Children who get authoritarian parenting at a younger age will have problems with external behavior, this will continue to develop and become an internal problem when the child grows up if they continue to get authoritarian parenting. Shifting problems that develop and are related to cognitive, physical, social maturity, and changes in social demands and expectations. ${ }^{10}$ Thus, permissive and authoritarian parenting styles can cause personality disorders in the adult phase of their offspring. ${ }^{11}$ The patient's father and grandmother had the same tendency as the patient, namely uncontrolled emotions and impulsive behavior. Research by KM Nautiyal et. al., found that there was a specific independent behavioral endophenotypes of impulsive behavior (5-HT1B). ${ }^{12}$

One of the personality disorders that can occur is borderline personality disorder (BPD). BPD is characterized by severe interpersonal dysfunction, emotional dysregulation, and a high risk of suicide. Although the causes of BPD are still difficult to understand, BPD is also associated with low core cognitive capacity in emotional regulation which is also influenced by genetics and the environment. the prevalence of BPD is more common in women than men. ${ }^{13}$ Increased neurological errors and less adaptive behavioral recovery from errors were found in authoritarian parenting. Continuous neural processing disruption of errors to improve performance can occur due to the behavior of parents who do not care. Significantly, the prediction of the neural index from performance monitoring differed between the behavior of the father and the mother, reflecting the difference in parental roles. ${ }^{14}$

In addition, parenting styles are also influenced by the parenting accepted by parents and culture. a Children often imitate their parents' rude behavior, causing them to rebel and act aggressively. So that a child has difficulty regulating his emotions as a consequence of authoritarian parenting. In another study, it was stated that a mother who experienced depression could also correlate with the child's behavior. ${ }^{6}$ Previous studies have found parental behavioral control to be positively related to self-control in their children, ${ }^{15}$ There are differences in findings in studies conducted on parenting between parents and children born in the 1990s with parenting between parents and children born above 2000. Older studies have found a positive relationship between authoritarian parenting and child self-control, ${ }^{15}$ where restrictions and monitoring carried out by parents can actually increase children's awareness to behave in an appropriate manner so that children can learn to control their own behavior. ${ }^{16}$

Alvares-Gracia found that impulsive antisocial behavior in adolescents was positively related to parental supervision and restriction. this is because adolescents may respond negatively to their parents' behavioral control, which further increases their impulsive and antisocial behavior. ${ }^{17}$ As previously 
mentioned, behavioral control carried out by parents is a risk factor for antisocial behavior, where this anti-social relationship has an indirect effect on impulsive behavior and is a risk factor for low empathy in adolescents. Antisocial

\section{CONCLUSION}

Young women who receive authoritarian care are more likely to be maladapted, stressed and exhibit impulsive behavior. In younger children, authoritarian parenting was associated with external behavior problems and in older children with internal behavior problems.

Impulsive behavior is also associated with genetic, authoritarian parenting or permissive parenting. These impulsive adolescents respond negatively to the behavior control exercised by their parents, so that the impulsive behavior can persist into early adulthood. One of the changes that occurred in adolescence and young adulthood was the decreased attachment to parents, where in young adulthood they were required to be independent. The friendship environment greatly influences the behavior and decisions that are taken. Antisocial friendships are also known to be an indirect risk factor for impulsive behavior. ${ }^{17}$

In addition, authoritarian parenting increases negative errorrelated (ERN) in emerging adult women, ${ }^{1}$ leading children to become adolescents who behave aggressively, ${ }^{2}$ perpetrators of bullying (traditional and cyberbullying). ${ }^{7}$ Therefore, the negative effects of authoritarian parenting must be prevented and anticipated. It is very important to provide appropriate parenting. In addition, parents must also be provided with information in order to avoid the negative effects of authoritarian parenting. ${ }^{6}$.

\section{REFERENCES}

1. Malakar, Partha., Mullick, Debaalena. Role of Parenting Style in Impulsivity and Perception of Stress among First Year College Students. International Journal Health and Research. Vol.8; Issue: 1; January 2018 p178-185.

2. Hentges, Rochelle F., Shaw, Daniel S., Wang, Ming-Te. 2017. Early childhood parenting and child impulsivity as precursors to aggression, substance use, and risky sexual behavior in adolescence and early adulthood. University of Pittsburgh.

3. Karimi, Sirwan., M. Pirmoradi, A. Ashouri, A. Aghebati. 2021. Relationship of Temperament and Character Traits, Emotional Regulation and Perceived Parenting With Self-harming Behaviors in Adolescents. Iranian Journal of Psychiatry and Clinical Psychology. Winter 2021, Volume 26, Number 4

4. Das, Tapasri., Mukherjee, Tilottama. Parent- Child Relationship in Adolescents with Borderline Personality Disorder- A Comparative Study. EAS J Psychol Behav Sci; Vol-2, Iss-4 (Jul-Aug, 2020): 84-89

5. Sarwar, Samiullah. 2016. Influence of Parenting Style on Children's Behaviour. Journal of Education and Educational Development. Vol. 3 No. 2 (December 2016)

6. Olla, Marice Benga., Daulima, N. H. Catharina, Putri, Yossie S. E. 2018. The experience of parents implementing authoritarian parenting for their schoolage children. Elsevier. Enferm Clin. 2018;28(Supl 1 Part A):122-125. behavior is used by adolescents so that they are accepted by their environment, or to increase their status in their environment or group. ${ }^{17}$.

7. C. Govender, K. Young. A comparison of gender, age, grade, and experiences of authoritarian parenting amongst traditional and cyberbullying perpetrators. South African Journal of Education, Volume 38, $\begin{array}{llll}\text { Supplement } & 1, & \text { October } & 2018 .\end{array}$ https://doi.org/10.15700/saje.v38ns1a1519.

8. Theresya, Julia., Latifah, Melly., Hernawati, Neti. The Effect of Parenting Style, Self-Efficacy, and Self Regulated Learning on Adolescents' Academic Achievement. Journal of Child Development Studies. 2018, Vol. 03, No. 01, page 28-43

9. Ahmad, S. I., \& Hinshaw, S. P. (2017). Attentiondeficit/hyperactivity disorder, trait impulsivity, and externalizing behavior in a longitudinal sample. Journal of Abnormal Child Psychology, 45, 1077-1089. http://doi.org/10.1007/s10802-016-0226-9

10. Kuppens, Sofie and Ceulemans, Eva. Parenting Styles: A Closer Look at a Well-Known Concept. Journal of Child and Family Studies (2019) 28:168-181. https://doi.org/10.1007/s10826-018-1242-x

11. N. Batool, H. Shehzadi, M. N. Riaz, et al. Paternal malparenting and offspring personality disorders: Mediating effect of early maladaptive schemas. Vol. 67, No. 4, April 2017

12. KM Nautiyal, MM Wall, S Wang, VM Magalong, SE Ahmari, PD Balsam, C Blanco, R Hen. Genetic and Modeling Approaches Reveal Distinct Components of Impulsive Behavior. Neuropsychopharmacology (2017) 42, 1182-1191

13. C. Skoglund, A. Tiger, Christian R.,P. Petrovic, Philip A., Clara H., David M.C., Ralf K. H. Familial risk and heritability of diagnosed borderline personality disorder: a register study of the Swedish population. Molecular Psychiatry 2621) 2699-1008. https://doi.org/10.1038/s41380-019-0442-0.

14. Banica, Iulia., Sandre, Aislinn., Weinberg, Anna. Overprotective/authoritarian maternal parenting is associated with an enhanced error-related negativity (ERN) in emerging adult females. International Journal

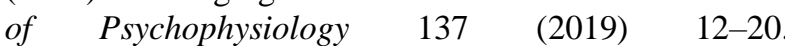
https://doi.org/10.1016/j.ijpsycho.2018.12.013

15. Li, D., Zhang, W., and Wang, Y. (2015). Parental behavioral control, psychological control and chinese adolescents' peer victimization: the mediating role of self-control. J. Child Family Stud. 24, 628-637. http://doi.org/10.1007/s10826-013-9873-4

16. Villanueva, V. J., and Serrano, S. (2019). Patrón de uso de internet y control parental de redes sociales como predictor de sexting en adolescentes: unaperspectiva de género. Revista De Psicol. Educ. 14, 16-26. http://doi.org/10.23923/rpye2019.01.168

17. Alvarez-Gracia, D., Paloma G.C., J. Carlos N., C. Rodriguez, R. Cerezo. Impact of Family and Friends on Antisocial Adolescent Behavior: The Mediating Role of Impulsivity and Empathy. Frontiers in Psychology $\begin{array}{llll}\text { Volume } & 10 . & \text { September } & 2019 .\end{array}$ http://doi.org/10.3389/fpsyg.2019.02071 